\title{
The Application of the ADDIE Model and the Training Cycle in the Development, Implementation and Evaluation of Training Program on Data Use for Decision-making among End-users of Electronic Health Information System in Geographically Isolated and Disadvantaged Areas
}

Jonathan P. Guevarra, RN, RM, MAN, ${ }^{1}$ Arturo M. Ongkeko Jr., RN, ${ }^{2}$ Carl Abelardo T. Antonio, MD, MPH, ${ }^{3}$ Amiel Nazer C. Bermudez, MD, $\mathrm{MPH}^{4}$ and Portia H. Fernandez-Marcelo, MD, $\mathrm{MPH}^{2}$

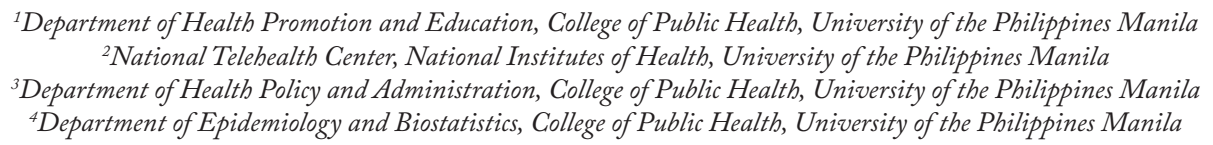

\begin{abstract}
Objective. This paper describes the process utilized in developing a training program on data use for decisionmaking tailored for real-time monitoring of maternal and child health indicators through Community Health Information Tracking System (rCHITS) end-users in selected areas in the Philippines.

Methods. Guided by the ADDIE (Analysis, Design, Development, Implementation and Evaluation) model and the training cycle, existing records and reports lodged with the National Telehealth Center (NTHC) pertaining to rCHITS were reviewed, supplemented by interviews with the technical staff of the NTHC and discussion with healthcare workers. Training design was developed, training modules and materials were prepared, critiqued, revised and finalized. The training was implemented and evaluated using an evaluation tool designed for this specific capability-building endeavor.
\end{abstract}

Results. A tailored training program on data use for decision-making was designed for rCHITS end-users in select areas in the Philippines. The process of developing the training program was guided by the ADDIE Model and the Training Cycle. Training was delivered to a total of 128 public health workers. Majority of the participants gave high evaluation on the clarity and relevance of objectives, discussion of topics, methods of delivery, and time devoted in addressing issues (range 3.5-3.8 out of highest possible score of 4).

Conclusion. This paper demonstrates the utility of the ADDIE Model and the Training Cycle in developing a training program aimed at enhancing the capability of the field personnel in utilizing the data generated from rCHITS in decision-making. Training participants must also be monitored and evaluated in their workplace setting in order to determine if the concepts and principles covered during the training program are put into practice.

Key Words: ADDIE Model, training cycle, data use, decision-making, end-users, rCHITS, Philippines

Corresponding author: Jonathan P. Guevarra, RN, RM, MAN Department of Health Promotion and Education College of Public Health, University of the Philippines Manila Lara Hall Building, 625 Pedro Gil Street,

Ermita, 1000 Manila, Philippines

Telefax: +6325260811

Email: jpguevarra2@up.edu.ph

\section{INTRODUCTION}

Decision-making is characterized as a pervasive, facilitative activity that permeates all functions of management. The necessary selection of alternatives that arise whenever institutions or organizations are faced with 
problems or opportunities trigger a process where managers: define and analyze the current scenario; formulate, assess, and choose among alternatives; and implement and evaluate the decision thus made.

In health care, decisions range from personal clinical care management to strategic (e.g., what is the mission and objective of the organization), to programmatic (e.g., what will be accomplished, and how it will be achieved), to operational (e.g., what resources are needed, and how to acquire them) types. This can generally be characterized as either programmed (i.e., routine) or non-programmed (i.e., contingent) decisions. While the decision-making process is assumed to take place in a rational, orderly manner, the reality is that it is characterized by disorder and emotionality, especially in circumstances when groups, instead of individuals, are given this task. Decision-making implies a change of state on the decision maker's side and information plays a vital role in determining which decision or choice is made. ${ }^{1}$

Of specific interest, actors in the public health sector are confronted with a peculiar set of decision-making circumstances. First, the impact of decisions made in healthcare determine the state of well-being achieved by individuals they render care to and the group of individuals similarly healthy or afflicted with the same disease condition. There can be dire consequences from decisions of not acting soon enough, say as in the case of when dengue fever is detected in the community. Certain diseases arise within very short timeframes, necessitating quick decisions. Third, resources are almost always finite, and funding for public health is generally sourced from the state and processes to mobilize this are often unwieldy.

Given the above premises, there is a need for decisionmaking in health, most especially in public health programs, to be guided and informed by best available evidence from individual patient records and programmatic reports. Healthcare workers will need to be capacitated in this regard if better health outcomes are to be achieved. Data-based decision-making promotes a rational and linear approach in setting and achieving clear goals through an objective analysis of possible alternative strategies and choosing one which will increase the probability of success. Furthermore, data can be used as a basis to measure progress during implementation and make strategy amendments should there be a need for it. ${ }^{1}$ Collection and utilization of health information for improved health outcomes are highly dependent on the decision makers' capability to make use of the data to effectively determine problems, define priorities, provide innovative solutions, and properly allocate resources. ${ }^{2}$ This was the goal when the University of the Philippines Manila (UPM) developed and implemented the Community Health Information Tracking System (CHITS) in 2004. CHITS is an electronic medical record (EMR) system designed to improve the quality and management of health information generated by a typical urban government health center or rural health unit (RHU)., 3,4
In 2011, the National Telehealth Center (NTHC) of the National Institutes of Health and UPM, in partnership with United Nations Children's Fund (UNICEF) further expanded CHITS to cover more relevant use of cases for the health workers in the field as well as to assist local chief executives (LCEs) in decision-making. This project, rCHITS or 'Real-time Monitoring of Maternal and Child Health Indicators through the use of CHITS,' aimed to foster an information and communications technology (ICT)-enabled health system and an information-based culture among local health professionals and leaders.

The CHITS is used by government physicians, public health nurses, and rural health midwives. It captures patientlevel clinical data, generates reports for the Philippine Health Insurance Corporation (PHIC), requires reimbursing the RHU services rendered to PhilHealth members, and produces aggregated reports required by the Department of Health (DOH). The current and second version uses the Open Medical Record System (OpenMRS) as its framework, and is implemented in 175 government rural health units. rCHITS expanded the CHITS platform and integrated the mobile Reports (mReports), an Androidbased application in a smartphone used by the rural health midwives as they render services in remote village health stations. The mReports documents clinical data of patients, transmits these to a central database via Short Messaging Service (SMS) and synchronizes this with the CHITS at the RHU. The LGU Dashboard, a web application that visualizes aggregated clinical services rendered by the RHU, is hosted on a central server, accessible anywhere with Internet access and proper authentication.

rCHITS was implemented across three phases in 13 selected GIDA with high rates of maternal mortality and poverty incidence. A total of 365 health workers were trained to use rCHITS. The first phase involved three towns to identify human resource, technology, organizational, and policy concerns. It expanded to 10 other GIDA where the rCHITS tools were enhanced, and human resource and organizational processes were addressed. While end-users noted efficiencies in data capture, storage and retrieval as well as reports generation, one key implementation gap is how to promote more intensely the development of an information-based culture among local health leaders. ${ }^{5,6}$

While composite data is now more available for refining local health programs, data use for local decision-making is not an immediate consequence. There was a need to heighten appreciation for data quality among government leaders, and the overall strategic value of investing in information management systems. These were the aims of rCHITS's third phase in 2015 (rCHITS-3). 5,6

Continuing the capacity-building on data use for decision-making for rCHITS end-users was deemed important to the RHU health team already primed to improve their HIS. The NTHC included faculty of the UPM College of Public Health $(\mathrm{CPH})$ to lead this task. 
This paper describes the process of developing the training program. Appreciation for data quality among government leaders, and the overall strategic value of investing in information management systems - i.e. those introduced by the Project - were setup and demonstrated.,4

Specifically, this article presents the (1) assessment of training needs, (2) development of training design, and (3) evaluation of the training package on data use for decision-making among end-users of electronic health information system in geographically isolated and disadvantaged areas.

\section{METHODS}

\section{A. Framework in developing the training on data use for decision-making: the ADDIE Model and the Training Cycle}

The most widely used method for developing new training programs is called Instructional Systems Design (ISD). There are different ISD models but most are represented by the acronym ADDIE (Analysis, Design, Development, Implementation and Evaluation). ${ }^{7}$ These steps are logically sequenced and ensure a practical approach to designing a training program. In designing a training program, a specific process is followed called the Training Cycle. ${ }^{7,8}$ The training cycle begins before a training program is conducted and continues after the program has been completed. ${ }^{7}$ Figure 1 shows the components of the training cycle which are parallel to the ADDIE Model.

\section{B. Methods for the Assessing the Training Needs}

The training needs assessment involved review of records and reports of the NTHC on the rCHITS and supplemented by interviews with the rCHITS project staff. A focus group discussion was also conducted involving the RHU staff and field personnel where rCHITS was implemented (i.e.

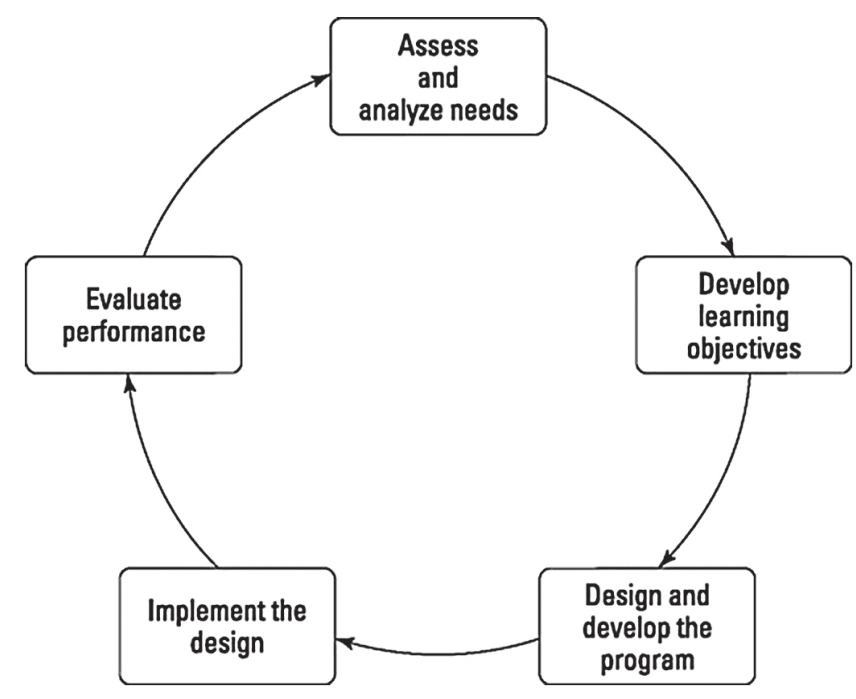

Figure 1. The Training Cycle.
Municipal Health Officer, Public Health Nurse, Rural Health Midwife).

\section{Development of the Training Package}

This involved developing the training design, presentation and critiquing of the design, training materials development, and finalization of the training package.

\section{RESULTS AND DISCUSSION}

\section{Process applied in developing the Training Package on Data Use for Decision-making}

\section{Assess and analyze needs}

This stage of the Training Cycle is called "Analysis" in the ADDIE Model. Assessment and analysis of the data was conducted in order to identify specific needs.

Establishing the rCHITS-3 implementation context in the bounds of decision-making allows sufficient progress in interpreting data to be useful for decision makers. Proper context is key to transforming data into useful information for strategic decision-making. ${ }^{9}$ Decision-making must also take into consideration the context of the preferences and values of those who will be affected by the decision. ${ }^{10}$

Records and reports of the NTHC pertaining to CHITS and rCHITS-2 (Phase 2) were reviewed. Of specific interest were the training workshops on data-use for decisionmaking implemented by the NTHC in 2014 in its CHITS implementation in Navotas City, and in the rCHITS-2 implementation in selected municipalities in Region 12 in 2015. These were guided by the Data Demand and Use (DDU) Framework. ${ }^{11}$ The DDU framework was deemed applicable in the CHITS and rCHITS sites. It stresses that the preliminary step - demand for data and information by managers and policymakers - triggers a cascade of data collection then data presentation in a format decisionmakers can understand. This consumable data reverts to decision-makers, which, in turn is utilized for strategic, programmatic, or operational purposes. Ultimately, such decisions are supposed to lead to an improvement in the health outcomes of the population being served.

Results of the review were supplemented with information gathered from interviews with CHITS and rCHITS project technical staff of the NTHC involved in the conduct of the training on data use in 2014 and 2015. In addition, the team had the opportunity to conduct a group discussion with the NTHC rCHITS RHU staff.

The instructional design to operationalize the framework in the context of rCHITS-2 was formulated by the NTHC and adopted from the document Tools for Data Demand and Use in the Health Sector published by USAID. ${ }^{12}$ The rCHITS-2 training package was divided into three modules: Building leadership for data demand and use; Linking data with action; and Identifying opportunities and barriers for improving data use. This was delivered through a 
combination of lectures, workshops and group discussions, and which are intended to help the trainee attain the following learning outcomes: (a) Describe the importance of data in the decision-making process; (b) Recognize the role of leadership in promoting sustainable data use; (c) Apply data demand and use (DDU) concepts, approaches and tools in the context of their locale; and (d) Develop specific plans to overcome barriers to data use.

The NTHC rCHITS-2 project team ensured that conceptually, the learning outcomes to be appropriately matched with the content, teaching-learning strategy, and method of evaluation. The progression of content was deliberately planned to show a demonstrable link between topics covered.

These DDU training implemented as part of the CHITS Navotas and rCHITS-2 implementations intended to develop that information-based culture among the local health professionals and leaders. However, the NTHC noted that application of learned cognates is not an immediate consequence, and thus not observed within its limited project timelines. The conditions were premature for this outcome, since the technologies, the CHITS EMR (in Navotas, in 2014) ${ }^{13}$ and rCHITS suite of integrated technologies (in Region 12, in 2015) were just recently introduced. These did transform the RHU's paper-based manual health information management system (HIS) to one that is automated, computerized and embeds elements of better health data quality. While DDU trainees in the target communities expressed appreciation for the need to manage more closely health programs based on these newly learned DDU principles, aligning current practices would need time, and operational and policy changes. ${ }^{13}$

These local health workers defined their HIS and data use: there were already established lines for reporting of data, and a clear delineation of the roles and responsibilities of the members of each local health team with respect to data generation and data use. While patient level data was for the immediate clinical care rendered by the health staff, the RHU aggregates the service data for submission to higher levels of the DOH (City or Provincial Health Office) for health program review. Local health center activities and budget were not always based on these aggregated $\mathrm{DOH}$ reports. Almost all DDU training participants were of the firm conviction that decision-making must be evidencebased, and that quality data is crucial to effective monitoring and evaluation of programs. Yet, the barriers on data use among local health personnel were identified to be technical, organizational, and behavioral in nature.

In summary, the primary concern of the three-day DDU training conducted previously was the assessment of data use perceptions and practices among health professionals and decision-makers at the local government unit level, as well well as an attempt to capacitate participants by introducing these DDU tools and techniques to enhance their use of data for decision-making.
Such strategy, while influenced by pragmatic considerations, has resulted to a conceptual discussion of data use for decision-making, instead of an applications course.

Given the foregoing, a revision of the training design was recommended by the $\mathrm{CPH}$ capacity-building team.

\section{Develop learning objectives}

After determining that there is a legitimate training need, the next step is to state exactly what the training is to accomplish. This step is similar to the "Design" phase of the ADDIE Model.

Using the results of the needs assessment, the following learning objectives were set that served as the basis in developing and designing the entire training program:

1. Develop a framework on work specialization and delegation in the context of data use for decision-making at the local health department level

2. Appraise health data generated by existing information management systems as to quality, validity and appropriateness

3. Implement appropriate course/s of action based on result of appraisal of existing health data.

\section{Design and develop the program}

This phase involves deciding exactly what to do to accomplish the objectives set. In the ADDIE model, this step corresponds to the "Development" phase of the training program.

In order to meet the learning outcomes for the training program, two (2) modules were developed (excluding the introductory module to the rCHITS Dashboard): Module 1: Data Use for Decision-making (3 sessions) and Module 2: Data analysis and presentation (3 sessions). The entire training design contains module objectives, session objectives, specific session contents, time frame, training methods/strategies, resources and evaluation methods (not presented in this article). Table 1 presents the contents (module and sessions titles) for the data use training program for rCHITS end-users.

\section{Module 1: Data use for decision-making}

This module introduces the concepts and tools related to evidence-informed decision-making, especially within the context of local health systems. This module is not designed to impart to front-line health workers what decisions need to be made for given circumstances, or data trends or patterns. Instead, the process and logic of evidenceinformed decision-making is what will be presented. Two assumptions underlie the construction of this module, and the presentation of its contents. First, the reader has prior knowledge of, and skills on, data processing, data analysis and data presentation, whether pertaining to paper-based or electronic records. And second, that the reader has had prior experience in decision-making, regardless of level or extent. A prerequisite for fully participating in the training 
Table 1. Training contents on data use for decision-making

\begin{tabular}{|c|c|c|c|}
\hline & Day 1 & Day 2 & Day 3 \\
\hline 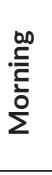 & $\begin{array}{l}\text { - Opening formalities } \\
\circ \text { Introduction of participants } \\
\circ \text { Expectations setting } \\
\circ \text { Overview of workshop } \\
\text { - Introduction to the rCHITS Dashboard }\end{array}$ & $\begin{array}{l}\text { - Data analysis and presentation } \\
\text { ○ Session 1: Variables } \\
\text { - Session 2: Summarizing qualitative } \\
\text { variables }\end{array}$ & $\begin{array}{l}\text { - Data Use for Decision-making: } \\
\text { ○ Session 2: Process of decision-making }\end{array}$ \\
\hline$\frac{\tau}{\frac{1}{4}}$ & $\begin{array}{l}\text { - Introduction to the rCHITS Dashboard } \\
\text { (continued) } \\
\text { - Data Use for Decision-making: Concepts } \\
\text { and Tools for the Front-line Health Worker } \\
\circ \text { Session 1: We are decision makers }\end{array}$ & $\begin{array}{l}\text { Data analysis and presentation } \\
\text { - Session 3: Summarizing quantitative } \\
\text { variables } \\
\circ \text { Session 4: Presentation of data }\end{array}$ & $\begin{array}{l}\text { - Data Use for Decision-making: } \\
\text { ○ Session 3: Aids for decision-making }\end{array}$ \\
\hline
\end{tabular}

Table 2. Participants during the training implementation

\begin{tabular}{|c|c|c|c|c|c|c|c|c|c|c|}
\hline \multirow{3}{*}{ Date } & \multirow{3}{*}{ Site } & \multicolumn{9}{|c|}{ Participants } \\
\hline & & \multicolumn{2}{|c|}{ Physicians } & \multicolumn{2}{|c|}{ Nurses } & \multicolumn{2}{|c|}{ Midwives } & \multicolumn{2}{|c|}{ Others } & \multirow{2}{*}{ Total } \\
\hline & & No. & $\%$ & No. & $\%$ & No. & $\%$ & No. & $\%$ & \\
\hline $\begin{array}{l}29 \text { February to } \\
4 \text { March } 2016\end{array}$ & $\begin{array}{l}\text { Lebak and Kalamansig, Sultan Kudarat; } \\
\text { President Roxas, North Cotabato }\end{array}$ & 3 & 5.45 & 6 & 10.91 & 45 & 81.82 & 1 & 1.82 & 55 \\
\hline 7 to 11 March 2016 & $\begin{array}{l}\text { Midsayap, North Cotabato; Aleosan, } \\
\text { North Cotabato; Malungon, Sarangani }\end{array}$ & 3 & 5.88 & 9 & 17.65 & 37 & 72.55 & 2 & 3.92 & 51 \\
\hline 14 to 18 March 2016 & $\begin{array}{l}\text { Buhangin District, Davao City; Arakan, } \\
\text { North Cotabato }\end{array}$ & 2 & 8.00 & 6 & 24.00 & 16 & 64.00 & 1 & 4.00 & 25 \\
\hline & Total & 8 & 6.25 & 21 & 16.40 & 98 & 76.50 & 4 & 3.10 & 128 \\
\hline
\end{tabular}

is a working knowledge of the various health programs being implemented by the local health department, including their respective monitoring and evaluation schemes. Module I is divided into 2 parts: Module $1 \mathrm{~A}$ : Concepts and Tools for the Front-line Health Worker and Module 1 B: Process of and Aids for Decision-making.

\section{Module 2: Data analysis and presentation}

This module introduces health workers to the descriptive analysis of qualitative and quantitative variables, including tabular and graphical presentation of data.

This training module utilizes a combination of lecturediscussions, workshops and plenary presentations to attain the learning outcomes and is intended to be delivered over a period equivalent to 24 contact hours. In the long run, attainment of the learning objectives will be evaluated through monitoring by field staff of actual use of decisionmaking in the workplace within three months following the training. The focus of the evaluation will be the process, and not necessarily the outcome, of decision-making.

\section{Implement the design}

This phase of the training cycle presents the implementation of the training program. In the ADDIE Model, this step is called the "Implementation" phase. Out of the 13 rCHITS sites nationwide, the training program was implemented in eight GIDA sites in Mindanao.

During the actual implementation of the training program done across two weeks in 2016, a total of 128 public health workers were trained on data use for decisionmaking. The three-day training event was conducted onsite and was participated by Rural Health Midwives (76.5\%), Public Health Nurses (16.4\%), Rural Health Physicians (6.25\%) and others (3.1\%) which included LCEs and representatives from the Municipal Council. LCEs of Lebak, Kalamansig and Midsayap with their respective Councilors for Health also graced the event for about a day. Table 2 summarizes the number of participants during the implementation of the training.

\section{Evaluate performance}

This phase of the training cycle presents the evaluation of the training program. This step in the training cycle is called the "Evaluation" phase in the ADDIE Model. The evaluation of performance presented in this section deals only with the performance of the participants/trainees during the conduct of the training program. It must be noted that true performance can only be determined in the workplace setting where the concepts and principles learned during the training program are put into practice. An assessment of performance is vital in evidence-based public health practice to ensure that community members are engaged in decision-making processes and that data use has led to sound evaluation of programs. Evaluation also allows identification of barriers to effective data-based decision-making. ${ }^{11}$ When more users are engaged in data-informed decision-making, higher value is placed on data and the more they are likely to utilize it. Regular use of data leads to a stronger demand for quality data in decision-making processes. Consequently, quality data is a vital tool in improving service delivery and health outcomes. ${ }^{12}$ 
The method of evaluation during the training was primarily through an evaluation tool that covered the following parameters: Clear and relevant objectives; Stimulating, interactive and comprehensive discussion about the topic, Method of delivery and performance of training staff (Effective and Engaging resource persons or Facilitators; Appropriate time to address the issues in each topic). The respondents were asked to score each topic using a 4-point rating scale, where 4 as the highest and 1 as the lowest.

\section{Module 1 A: We are all decision-makers!}

Four topics and two workshops were evaluated during the first day of the training. These modules included: $r$ CHITS $L G U$ Dashboard and LGU Health Scorecard, Levels and domains of decision-making, Decision-makers in Healthcare Organizations, and Workshops 1 and 2.

A total of 114 (90\%) of the 128 participants were able to complete the evaluation. Out of the four topics, the second topic, We are all decision-makers!, received the highest evaluation from the respondents with a mean score of 3.76 out of 4 while the first topic, rCHITS LGU Dashboard and $L G U$ Health Scorecard, received the lowest evaluation with a mean score of 3.61 out of 4 . Since it was the first topic, the participants may have needed more time to be able to understand the concepts and adjust with the flow of discussions. Workshop 2 was the most appreciated activity with a mean score of 3.78 out of 4 while Workshop 1 was the least appreciated activity with a mean score of 3.73 out of 4 . Figure 2 summarizes the mean scores of all the training sessions for Day 1.

The participants felt that facilitators were able to allot sufficient time to address the issues in each topic (mean score of 3.73 out of 4) however, they also reported that discussion of the objectives needed to be improved. In general, the participants had positive reactions for the sessions. They found the topics and workshops to be informative and relevant to their field and useful in their work. Figure 3 summarizes the mean scores of each evaluation parameter for all the training sessions.

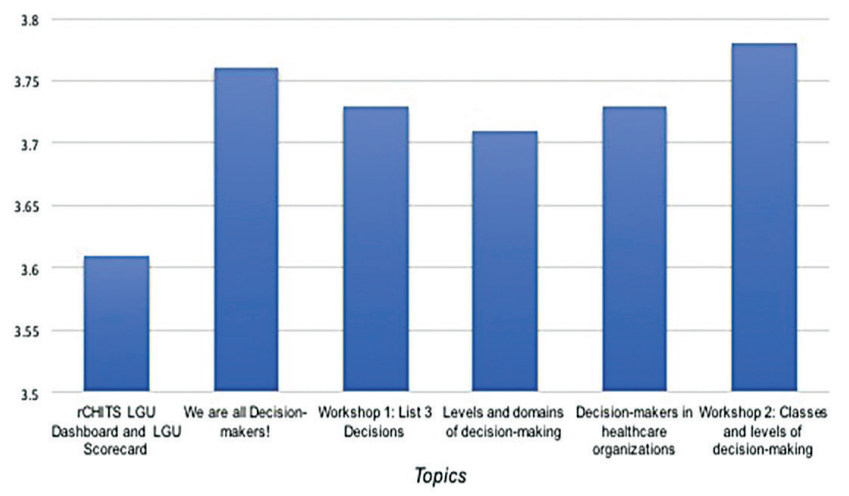

Figure 2. Mean scores of participants' evaluation on the topics and workshops from the training (Day 1 ).
Module 2: Introduction to data analysis and presentation

Four lectures and seven exercises were evaluated during Day two. These modules include: Variables and Scales of Measurements, Summarizing Qualitative Variables, Summarizing Quantitative Variables, Presentation of Data, and Exercises 1 to 7.

The third topic, Summarizing Quantitative Variables, received the highest evaluation from the respondents with a mean score of 3.75 out of 4 while the first topic, Variables and Scales of Measurements, received the lowest evaluation with a mean score of 3.66 out of 4 . Among the seven exercises, the third exercise on frequency distribution table was the most appreciated activity with a mean score of 3.77 out of 4. The least appreciated activity was the fourth exercise with a mean score of 3.65 out of 4 . Figures 4 and 5 summarizes the mean scores of all the training sessions from Day 2. According to the respondents, the facilitators were able to allot sufficient time to address questions and issues during the training (mean score of 3.73 out of 4 ) but the clarity and relevance of the objectives need further improvement (mean score of 3.68 out of 4 ). Figure 6 summarizes the mean scores of each evaluation parameter for all the training sessions. Nevertheless, the sessions were generally perceived by the participants to be good and interesting. For most of the participants, the sessions were very informative and perceived to be an additional learning in their respective fields.

\section{Module $1 \mathrm{~B}$ : Process of and aids in decision-making}

The last day of the training covered two topics and workshops namely, Process of Decision-making, Aids for Decision-Making, and Workshops 1 and 2. Out of the two topics, the Process of Decision-making received a higher evaluation (mean score of 3.80 out of 4) than Aids for Decision-Making (mean score of 3.79 out of 4). Since it was the last topic discussed, the participants may have had difficulty in focusing on the last few topics tackled during the session. Also, the "concepts of and aids in decision-making" may not have been easy for them to digest in just a short

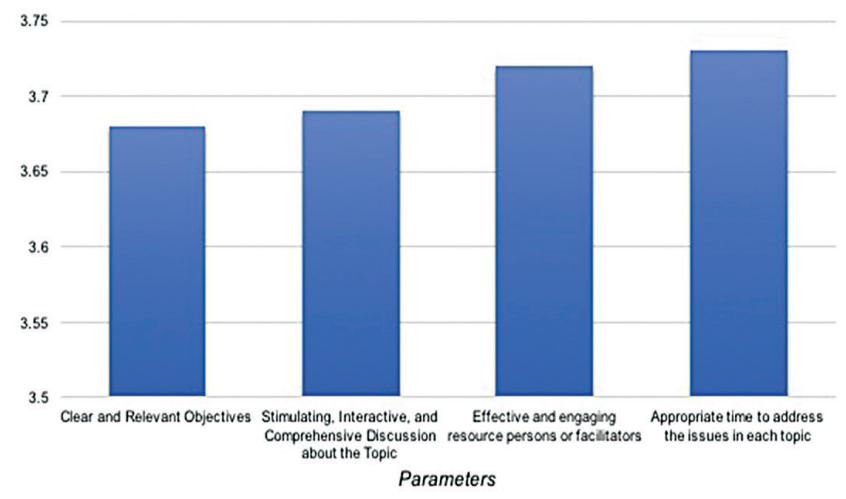

Figure 3. Mean scores of each evaluation parameter for all topics and workshops from the training (Day 1). 
span of time. Workshop 2 received the highest evaluation out of the two activities with a mean score of 3.78 out of 4. Workshop 1 received a mean score of only 3.74 out of 4. Figure 7 summarizes the mean scores of all the training sessions for Day 3.

Based on the participants' rating, they were most satisfied that sufficient time was allotted to address the issues in each topic and workshop (mean score of 3.83 out of 4 ). However, accordingly, discussion of the topics still needs further

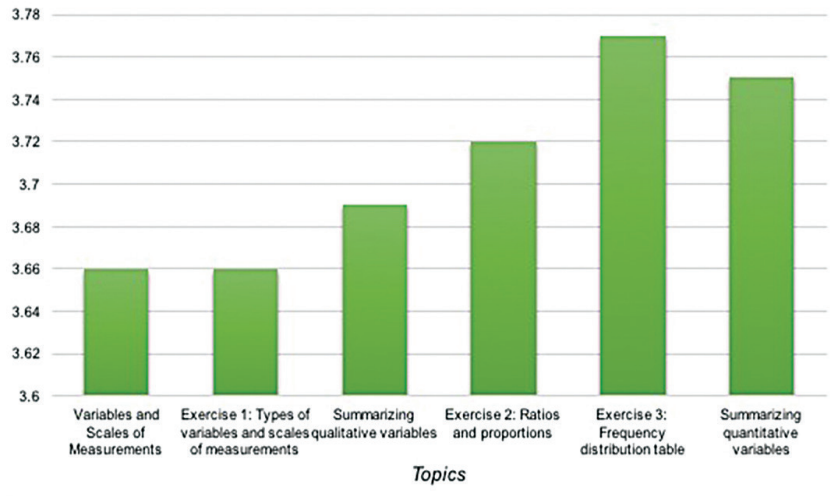

Figure 4. Mean scores of participants' evaluation on the topics and workshops from the training (Day 2, Part 1).

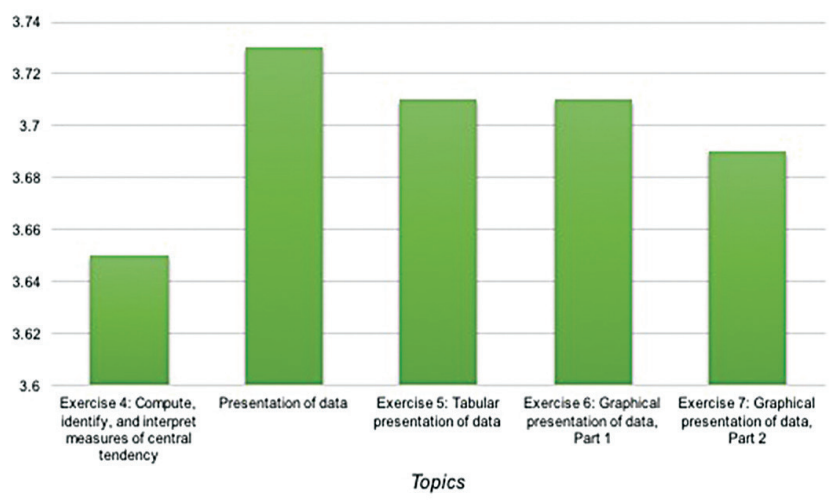

Figure 5. Mean scores of participants' evaluation on the topics and workshops from the training (Day 2, Part 2).

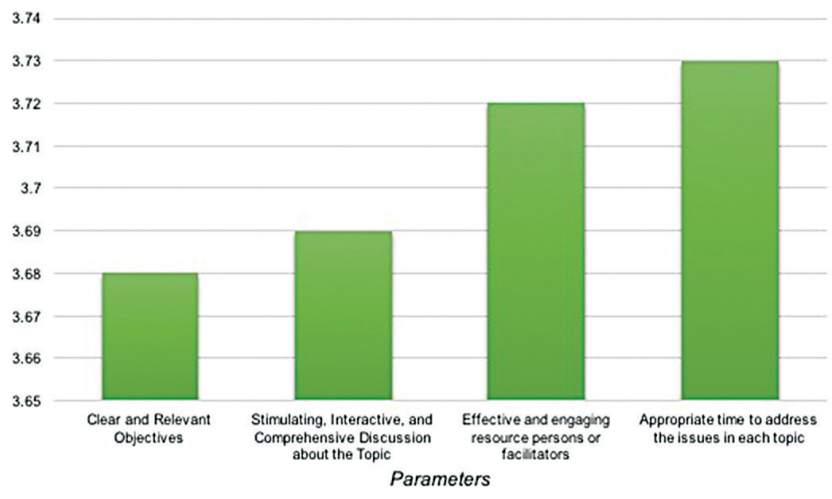

Figure 6. Mean scores of each evaluation parameter for all topics and workshops from the training (Day 2). improvement (mean of 3.74 out of 4 ). Figure 8 summarizes the mean scores of each evaluation parameter for all the training sessions. According to the respondents' evaluation, the third day had the clearest and most relevant objectives, the most stimulating, interactive and, comprehensive discussions, most engaging facilitators, and allotted sufficient time in addressing issues as compared to the training sessions conducted during the previous days. Overall, the participants provided a positive feedback on the last day's sessions wherein they perceived the topics and activities to be interesting, beneficial, and applicable in their work. Though there were a few participants who said these were stressful and confusing sessions, most still reported that these were clear enough and even boosted their learning and attitude towards decision-making.

\section{Limitations}

Review of records and reports were done as part of the training needs assessment supplemented by interviews with the NTHC technical staff and discussion with the end-users. It would have been better if a quantitative assessment using a questionnaire or test was conducted in addition to the methods used. This would have given a more comprehensive picture of the training needs of the participants. Evaluation

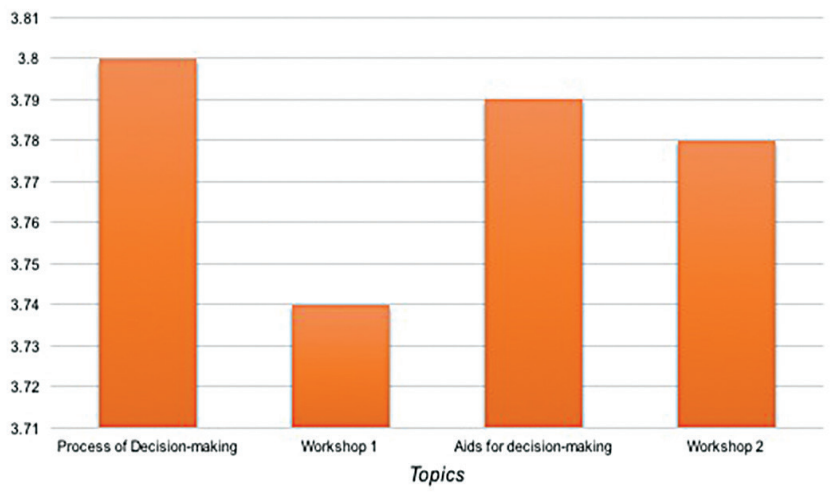

Figure 7. Mean scores of participants' evaluation on the topics and workshops from the training (Day 3).

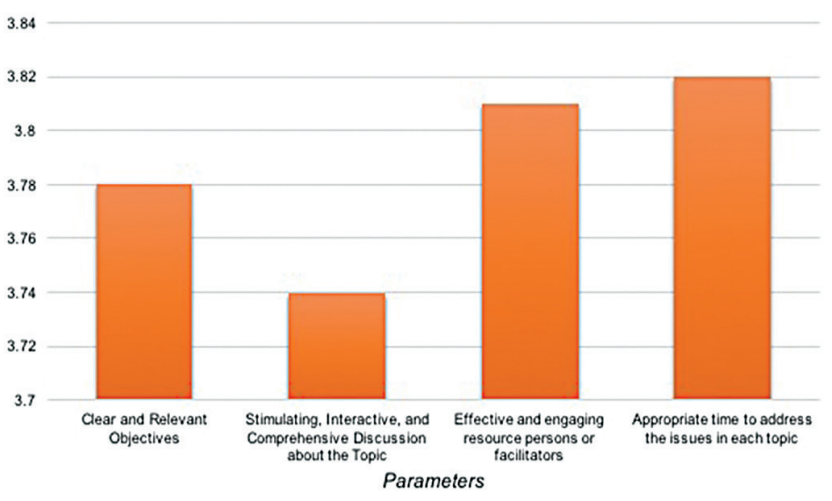

Figure 8. Mean scores of each evaluation parameter for all topics and workshops from the training (Day 3). 
was conducted only during the duration of the training program. In order to determine the true performance of the trainees, evaluation needed to be done in the field to determine if the data generated from the rCHITS were indeed used in decision-making process.

\section{CONCLUSIONS AND RECOMMENDATIONS}

This paper demonstrates the utility of the ADDIE Model and the Training Cycle in developing a training program aimed at enhancing the capability of the field personnel in utilizing the data generated from rCHITS in decisionmaking. In future similar endeavors, it is recommended that a combination of qualitative and quantitative assessments be utilized in order to have a more comprehensive picture of the training needs of the health care workers. Aside from the method of evaluation used in the training program, it is also recommended that training implementors include pretest and post-test in their evaluation method.

\section{Acknowledgments}

The authors would like to acknowledge the support provided by the UNICEF Philippines Joint Programme on Maternal and Neonatal Health (JPMNH), the local government and health staff of the eight RHU in Mindanao where rCHITS-3 was implemented.

\section{Statement of Authorship}

All authors have approved the final version submitted.

\section{Author Disclosure}

All the authors declared no conflicts of interest.

\section{Funding Source}

None.

\section{REFERENCES}

1. Kavale S. The Role of Data in Strategic Decision-Making Process. Int J Curr Res. 2012 Apr; 4(4):001-007.

2. Stansfiled SK, Walsh J, Prata N, Evans T. Chapter 54: Information to Improve Decision Making for Health. In: Jamison, DT, Breman JG, Measham AR, eds. Diseases Control Priorities in Developing Countries. New York: Oxford University Press; 2006.
3. Marcelo PF. Chapter 9: Community Health Information and Tracking System: Quality Care through Information Management. In: Partnership Matters: Lessons from a Decade of Collaboration between the UP College of Medicine and Pasay Coty, Moving from Theory to Practice: Academic Community Medicine in an Urban Setting: University of the Philippines College of Medicine. 2010.

4. Ongkeko Jr AM, Fernandez RG, Sylim PG, Amoranto AJP, RonquilloSy MI, Santos ADF, et al. Community Health Information and Tracking System (CHITS): Lessons from eight years implementation of a pioneer electronic medical record system in the Philippines. Acta Med Philipp. 2016 Oct-Dec; 50(4):264-79.

5. National Telehealth Center, National Institutes of Health, University of the Philippines Manila. rCHITS2: Real Time Monitoring of Key Maternal and Child Health and Governance Indicators through the Community Health Information and Tracking System, mReports, and the Local Government Unit Dashboard. Basic Electronic Health Information System Management Data Manager's Manual. 2014.

6. National Telehealth Center, National Institutes of Health, University of the Philippines Manila. Community Health Information Tracking System: User Manual. 2013.

7. Biech E. The Training Cycle. In: Training for Dummies [Internet]. 2011 [cited 2016 Dec 31]. Available from: https://books.google.com. ph/books?id=1ZWj6GPqDGUC\&pg=PA39\&lpg=PA39\&dq=train ing + cycle \& source $=b 1 \& o t s=n 4 e K Z D X 3+E \& s i g=8 \mathrm{Ca} 4 \mathrm{cO} z b O b J b z i 5$ htVM98IHnVno\&hl=en\&sa=X\&ved=0ahUKEwi677PSnJzRAhU MjJQKHVhYD884ChDoAQgwMAQ\#v=onepage\&q=training\%20 cycle\&f=false

8. Dhawan S. Systematic Approach to Training: Main Phases of the Training Cycle [Internet]. [cited 2017 Jan 1]. Available from: http:// www.topconsultant.com/articles/the \%20systematic\%20approach\%20 to\%20training.pdf

9. Grimshaw DJ, Mott PL, Roberts SA. The role of context in decision making: some implications for database design. Eur J Inf Sys. 1997 Dec; 6(2):122-8. doi.org/10.1057/palgrave.ejis.3000261

10. Teutsch S. Generating Evidence for Decision Making. In: Institute of Medicine (US) Roundtable on Translating Genomic-Based Research for Health, Systems for Research and Evaluation for Translating Genome-Based Discoveries for Health: Workshop Summary. Washington, DC: National Academic Press. 2009.

11. Jacob RR, Baker EA, Allen P, Dodson EA, Duggan K, Fields R, et al. Training needs and supports for evidence-based decision-making among the public health workforce in the United States. BMC Health Serv Res. 2014 Nov; 14:564. doi: 10.1186/s12913-014-0564-7.

12. Nutley T. Improving Data Use in Decision Making: An Intervention to Strengthen Health Systems [Internet]. 2012 [cited 2017 June 8]. Available from: https://www.measureevaluation.org/resources/ publications/sr-12-73

13. National Telehealth Center, National Institutes of Health, University of the Philippines Manila. CHITS Navotas Phase 2 Final report: Strengthening health system governance in Navotas through data/ information driven decision-making. 2014. 